\title{
As construções de desejo em português
}

\author{
Constructions of desire in Portuguese
}

\section{Maria Lucia Leitão de Almeida Universidade Federal do Rio de Janeiro}

\begin{abstract}
This work examines grammatical constructions of desire in Brazilian Portuguese. It observes that there is a constructional network, with polissemy links. The paper analyses also the importance of transitivity and control for characterization of such constructions.
\end{abstract}

\section{Keywords}

Grammatical constructions; Transitivity; Control.

\section{Resumo}

Este artigo examina as construções de desejo em português brasileiro. Observa-se que há uma rede construcional com ligações polissêmicas. Analisa-se a importância da transitividade e do controle para a caracterização de tais construções.

\section{Palavras-chave}

Construções gramaticais; Transitividade; Controle. 


\section{Aspectos gerais: $O$ modelo das construções gramaticais}

$\mathrm{O}$

modelo das construções gramaticais, conforme proposto formalmente

por Goldberg $(1995,2006)$ e também formulado por Langacker

(1987), Kay \& Fillmore (1999) e Culicover (1999), Croft (2001) tem

enfatizado o papel das construções na estruturação da gramática. Naturalmente, a idéia atual não é simplesmente aquela velha afirmação de que há construções, como as passivas, por exemplo, mas sim uma visão de que a gramática é essencialmente feita por um grande conjunto de construções que formam um sistema interconectado, uma rede. Tempos atrás, tal visão de inventário era considerada não-realística, sobretudo por causa do custo da aquisição (TOMASELLO, 2000). Atualmente, entretanto, dado o conhecimento de quanta informação o cérebro humano pode armazenar, associado ao conhecimento de processamento sintático on-line (FARRIÑA, 2006), retorna-se à noção de construção como o princípio organizador da gramática.

Tal visão vem se mostrando altamente produtiva para explicação de fenômenos lingüísticos, tanto os de ordem morfológica quanto os de ordem sintática e semântica. No que tange ao primeiro, o Núcleo de Estudos Morfossemânticos do Português (NEMP ${ }^{1}$ ), que funciona na UFRJ, vem se debruçando sobre os estudos dos padrões construcionais de formas derivadas por processos nãoconcatenativos. No que diz respeito ao segundo, dissertações de mestrado e teses de doutorado vêm descrevendo e analisando construções, sobretudo aquelas que envolvem questões de polissemia, como mostra, por exemplo, Silva (1997), em relação ao verbo deixar. O verbo "deixar", grosso modo, tanto pode ter um uso como permitir (Deixei que as crianças saíssem) quanto um uso de retirar-se, afastar-se (Deixei-os na sala), entre outros. Observe-se, entretanto, que as estruturas sintáticas são também diferentes. Na primeira, temos uma estrutura transitiva, com o argumento objeto direto preenchido oracionalmente; na segunda, o objeto direto é pronominal, seguido de um sintagma preposicional locativo argumental. 
Tais configurações permitem que outros verbos com elas se compatibilizem, assumindo similarmente os sentidos de permissão ou abandono, que são significados construcionais. É assim que ocorre, para o primeiro caso, aceitar, resignar-se, cujos significados mais básicos não são o de permissão, mas que tomam esse valor na construção. A verificação da evidência da contribuição do significado construcional, e não somente lexical, pode ser feita ao se tentar compatibilizar os mesmos verbos na outra construção de "deixar". As sentenças tornam-se agramaticais: *Aceitei-os na sala; *Resignei-os na sala.

O modelo das construções gramaticais, portanto, permite uma descrição eficiente das fórmulas das línguas, ao propor, basicamente, que:

A) a unidade lingüística a ser considerada é a construção gramatical (CG), ou seja, um pareamento forma/significado, de tal maneira que nenhum aspecto de um possa ser previsto independentemente do outro;

B) as CGs existem em quaisquer dos níveis lingüísticos - do fonológico ao sintático.

Então, as CGs, que compõem um sistema estruturado e relacionado por ligações de herança são asseguradas pelos seguintes princípios gerais:

1) Princípio da motivação maximizada

Se uma construção A está relacionada a uma construção B sintaticamente, então o sistema da construção Aé motivado em algum grau e está relacionado à construção $\mathrm{B}$ semanticamente.

2) Princípio da não-sinonímia

Se duas construções são sintaticamente distintas, então elas devem ser semântica ou pragmaticamente distintas.

Corolário A: se duas construções são sintaticamente distintas e S(emanticamente) sinônimas, elas devem ser P(ragmaticamente) sinônimas.

Corolário B: se duas construções são sintaticamente distintas e Psinônimas, elas devem ser S-sinônimas.

3) Princípio do poder expressivo maximizado

O inventário das construções é maximizado por propósitos comunicativos. 
4) Princípio da economia maximizada

O número de construções distintas é minimizado tanto quanto possível, respeitado o princípio 3.

\section{O foco do trabalho}

O objetivo deste trabalho é estudar as construções que expressam desejo em português.

Há verbos que prototipicamente expressam desejo (embora não exclusivamente), como “desejar"e "querer", e outros que tomam essa acepção em determinadas construções, como "estimar","esperar". Há, ainda, as construções idiomatizadas com a interjeição "tomara".

Debruçar-se sobre as construções de um modo geral, e construções de desejo, especificamente, pouco estudadas na literatura e ainda não analisadas em português, envolve, além da tarefa descritiva de Construção Gramatical, um outro desafio teórico: lidar com a questão da informação lexical - o conhecimento propriamente lingüístico - e o conhecimento enciclopédico, diretamente relacionado aos Modelos Cognitivos Idealizados, acionados quando expressões lingüísticas são postas em uso em determinadas construções. Para fins de clareza, tomemos um exemplo adaptado de Goldberg para o português: "Ele tossiu a espinha de peixe no guardanapo". O verbo "tossir", no caso, assume um valor de movimento voluntário que causa um efeito (a expulsão da espinha de peixe) graças à construção em que ele está inserido (a de movimento causado). Então, a sua informação lexical (ação involuntária orgânica) é adaptada ao significado construcional, fruto da conceptualização do evento (necessidade de expulsão de espinha presa na garganta), ou seja, ao MCI do evento.

Por serem os MCIs culturalmente estabelecidos, as diferentes línguas terão construções diferentes para expressar diferentes cenas. Por isso, este trabalho basear-se-á em corpus fundamentado no uso.

\section{Metodologia}

\subsection{Procedimentos analíticos:}

Para se proceder ao estudo das construções que expressam desejo em português realizaram-se os seguintes passos: 
1) determinação do verbo querer como ponto de partida para identificação da(s) estrutura(s) associadas com a semântica do desejo;

2) levantamento das suas entradas em dicionários prestigiados para recortaremse aquelas que são o foco de análise;

3) análises de suas estruturas sintáticas e características semânticas para traçar a(s) construção(ões);

4) coleta de dados via ferramentas de busca eletrônicas;

5) análise qualitativa dos exemplares colhidos na busca eletrônica cotejados com os padrões anteriormente estabelecidos (cf. 4);

6) teste dos padrões construcionais com os outros verbos;

7) repetição dos procedimentos estabelecidos nos itens de 2 a 6 com cada verbo que pode expressar desejo.

Observe-se que a necessidade de usar a dedução (1 a 5) e a indução(6) se deve ao duplo aspecto do significado explicado no item anterior.

\subsection{Ferramentas eletrônicas de busca e corpora:}

As bases de dados utilizadas foram os inquéritos do NURC-RJ e os do projeto Discurso e gramática (D\&G-Rio), e o software UNITEX. Além disso, utilizouse o Google para verificar a existência de construções que eventualmente não estivessem representadas nos corpora organizados.

\section{Construções com o verbo "querer"}

De acordo com as entradas dicionarizadas (cf. 2 da metodologia), que revelam o conhecimento lingüístico, as construções sintáticas em que o verbo "querer" ocorre, com o significado de desejar, são sempre transitivas, o que se explica, já que o processo de desejo é, por sua própria experiência psicológica, transitivo.

A transitividade pode ser realizada com OD simples ou oracional e, neste último caso, em estruturas finitas ou infinitivas, como pode ser verificado a seguir, com exemplos do corpus obtido por meio do Google.

O Dicionário do Houaiss, por exemplo, lista 23 entradas diferentes para o verbo "querer" associadas a diferentes transitividades (direto, indireto, 
bitransitivo, intransitivo), relacionadas por sua vez a diferentes subdeterminações lexicais (ex: 14 - exigir - ex.: quem trabalha na terra quer terra).

Observe-se que essas subespecificações são função da construção em que o "querer" está ocorrendo. É o que acontece no exemplo acima: há um incremento de "querer", que ganha a acepção de "exigir" graças às outras informações lexicais e à construção em que se encontra, típica de provérbio, que traz na segunda oração uma conclusão (Quem semeia ventos colhe tempestade; quem casa quer casa; quem tudo quer tudo perde, etc.).

Então, desconsideradas essas subespecificações, podem-se resumir as entradas com o sentido da expressão do desejo, conforme mostrado adiante, associadas aos seus padrões sintáticos.

Com OD realizado por $\mathrm{SN}$ simples:

\section{desejar, aspirar}

(1) Não quero dinheiro. Quero amor sincero. (suj-exp.volitivo /objeto - coisa desejada)

(2) Acusaram-me de querer protagonismo.

(3) João quer seriedade neste projeto. (suj-exp. volitivo/ objeto desejado SN/ obl ${ }^{2}$ - "lugar" do desejo) OBL (oblíquo) = advérbio, sprep

Com OD realizado por $\mathrm{SN}$ oracional:

\section{desejar, aspirar}

Oração finita:

(4) Eu quero [que ele me traga um relatório completo].

(5) Quero [que os dois saiam daqui].

(6) Apesar do que aconteceu, ela não quis [que eu ficasse por perto].

(7) Quero [que você fique contente].

Oração infinitiva:

(8) Pare o mundo que eu quero [descer].

(9) Ainda não encontrei mulher com quem quisesse [ter filhos].

(10) Não houve quem quisesse [usar a palavra].

(11) Queria [ter uma camisa do Vasco nova!]. 
Análise preliminar indica, portanto, que "querer" é sempre transitivo e o objeto direto pode ser simples ou em forma de oração, finita ou infinitiva.

Em outras palavras, constata-se que as construções que expressam desejo envolvem crucialmente dois aspectos: a questão da transitividade e a das estruturas de controle. Passemos a elas, então.

\subsection{A questão da transitividade}

Ao analisar vínculos de ligação entre as construções, Goldberg (1995,p. 118) sugere que a construção transitiva pode ser vista como uma estrutura unitária, cuja semântica consiste de duas "protofunções", a construção transitiva é considerada como se possuísse um significado único, bastante geral, o que possibilitaria observar famílias de significados relacionados, com a prototípica "cena transitiva" sendo o sentido central. Nesse caso, o sentido central seria bem específico - um ator volicional afeta um paciente inanimado, estabelecendo assim um evento causativo. Extensões a partir do protótipo poderiam licenciar um grande conjunto de expressões transitivas.

A autora reconhece, entretanto, que as línguas diferem em como e em qual extensão construções transitivas são estendidas para expressar cenas transitivas semanticamente não prototípicas, como é o caso das construções com o verbo "querer".

Para estabelecer o grau de transitividade das construções, foram considerados, como sugerido em Goldberg (id, p. 116), os parâmetros traçados por Dowty (1991) para caracterização do proto-agente e do protopaciente:

\section{Propriedades de proto-agente:}

1) envolvimento volicional no evento ou estado;

2) experiência (e/ou percepção);

3) causação de evento ou troca de estado em outro participante;

4) movimento (relativo à posição de outro participante);

5) existência independente do evento nomeado pelo verbo.

\section{Propriedades de protopaciente:}

1) troca de estado;

2) tema; 
3) afetado causalmente por outro participante;

4) relativa imobilidade ao movimento de outro participante;

5) não existência independentemente do evento.

A essas propriedades é associado o "princípio de seleção do argumento" que diz o seguinte: "Em predicados com sujeito e objeto gramatical, o argumento que possui maior quantidade de propriedades de proto-agente será lexicalizado como sujeito; o argumento com mais propriedades de protopaciente será lexicalizado como OD".

A aplicação dessas propriedades e do princípio aos exemplos do corpus mostra que os sujeitos e objetos examinados se afastam do protótipo à medida que só apresentam as propriedades 1, 2 e 5, da lista de proto-agente, e 2 a 5 da de protopaciente.

Essa primeira análise permite algumas conclusões parciais:

a) o comportamento dos sujeitos e dos verbos, sob o aspecto semântico, é consistente em todos os dados examinados (100\%), o que aponta para uma macroconstrução (CG) que instancia $p$ desejo;

b) tal construção integra a rede das construções transitivas, das quais herda algumas propriedades;

c) a análise da transitividade, exatamente por causa de seu resultado homogêneo, é insuficiente para capturar as peculiaridades das diferentes construções da rede do desejo.

A formalização das conclusões (a) e (b) pode ser assim realizada.

\section{Macroconstrução do desejo}

\begin{tabular}{|c|c|}
\hline $\begin{array}{c}\text { SEM } \\
\text { Exp (volicional/com existência independente) }\end{array}$ & $\begin{array}{c}\text { PACIENTE } \\
\text { (tema-inexistência fora do evento) }\end{array}$ \\
\hline SINTAXE SUJEITO & OBJETO \\
\hline
\end{tabular}

A formalização apresentada indica que essa macroconstrução herda parcialmente características da construção transitiva prototípica e, portanto, deve 
ser dela derivada. Entretanto, diante da limitação da análise da transitividade, examinemos as condições de controle.

\subsection{A questão do controle}

Questão clássica da Lingüística, a questão de controle também se faz pertinente numa perspectiva construcional.

Diferentemente do que se verifica na perspectiva gerativista da Teoria da regência e ligação (CHOMSKY, 1981), em que são estudadas as condições de controle exclusivamente sintáticas, a teoria construcional busca dar conta das condições sintáticas e semânticas para as relações de controle.

Goldberg (1995) mostra relação de dominação entre construções (mesmo porque ela trabalha com períodos simples).

Langacker $(2007)^{3}$ apresentou proposta para dar conta de aspectos semânticos-sintáticos de orações sob controle, partindo do ponto de vista do sujeito cognitivo, do modo como ele conceptualiza e realiza lingüisticamente o evento representado na oração encaixada.

Em termos sintáticos, ele observou se a oração encaixada estava em tempo finito ou nominal (infinitivo).

Em termos semânticos, ele verificou que o controle exercido pela oração principal poderia ser ou efetivo ou epistêmico.

O controle efetivo especifica o participante central no evento complementar; o epistêmico especifica o conceptualizador da proposição complemento.

(12) João gosta de dançar. (Foco no participante do evento complemento.)

(13) João gosta que Maria dance. (Foco no sujeito da conceptualização.)

Tais análises apontaram para uma regularidade padrão sintático/valor semântico já que o valor epistêmico ocorre com as orações finitas, enquanto o efetivo com as orações infinitas.

O autor propõe ainda uma escala que avalia a efetividade da realização do evento, efetividade essa que pode ser vista a seguir:

Potencial< inclinação<intenção < decisão < preparação<execução<resultado.

Exemplos:

(14) Potencial - Ela ensinou Maria a cozinhar. 
(15) Inclinação - Ele sabia como preparar um pudim.

(16) Intenção - João persuadiu Maria a preparar o jantar.

(17) Decisão - Ele resolveu preparar o jantar.

(18) Preparação - Ele se esforça para assar a carne.

(19) Execução - Ele tentou cozinhar a carne.

(20) Resultado - Ele conseguiu assar a carne.

Similarmente, Langacker desenvolveu uma escala para o controle epistêmico, que assim se configura:

Potencial< inclinação<projeção<execução<resultado.

Exemplos:

(21) Potencial - As crianças podem ficar desapontadas.

(22) Inclinação - As crianças parecem estar desapontadas.

(23) Projeção - As crianças indicam estar desapontadas.

(24) Execução - As crianças começam a ficar desapontadas.

(25) Resultado - As crianças demonstram estar desapontadas.

A conclusão a que chega o autor é que, quando o complemento é infinito, tem-se a efetividade da conceptualização, então o status atribuído ao evento da encaixada é de versão da realidade. No entanto, se o complemento é finito, dado seu caráter epistêmico, o que é acessada é a proposição, que não significa que seja real.

\section{Aplicação dos parâmetros de Langacker aos exemplos com o verbo "querer"}

Com OD realizado por $\mathrm{SN}$ oracional:

\section{Oração finita: EPISTÊMICAS}

(26) Eu quero [que ele me traga um relatório completo]. (projeção)

(27) Quero [que os dois saiam daqui]. (projeção)

(28) Apesar do que aconteceu, ela não quis [que eu ficasse por perto]. (projeção) 


\section{Oração infinitiva: EFETIVAS}

(29) Pare o mundo que eu quero [descer]. (decisão)

(30) Ainda não encontrei mulher com quem quisesse [ter filhos]. (inclinação)

(31) Não houve quem quisesse [usar a palavra]. (potencial)

(32) Queria [ter uma camisa do Vasco nova!]. (intenção)

(33) Quero [que vc fique contente]. (potencial)

(34) Gostar de mulher é querer [fazer a mulher feliz] (Infinitivo). (decisão)

A aplicação desses parâmetros mostrou que, ratificando a proposta de Langacker, quando a encaixada é infinitiva, o sujeito cognitivo atribui status de real ao evento. Interessante, nesse sentido, examinar duas ocorrências no corpus de oração condicional em que a prótase é realizada por estrutura de controle com o verbo querer + infinitivo.

(35) [Se eu não quisesse[ usar antivírus]], meu computador estaria em risco.

(36) [No dia quando eu quisesse[ morrer]/Acordaria logo cedo após o dia nascer..

Observe-se que, mesmo o verbo "querer" estando no subjuntivo, a oração encaixada infinitiva toma o status de realidade; tanto é que o sujeito conceptualizador desenvolve a conclusão em função do cenário traçado a partir do desejo.

A aplicação desses parâmetros de análise à amostra das construções de desejo revela que as construções de desejo:

1) apresentam seus status de efetividade ou de "epistemicidade" regularmente distribuídos, como previsto por Langaker, pelas orações infinitas e finitas.

2) verifica- se, ainda, que há uma variação do modo como são realizadas tanto a efetividade quanto a "epistemicidade". No que diz respeito à primeira , as ocorrências vão variar de "potencial" a "decisão"; no que diz respeito à segunda, variam entre "inclinação"e "projeção".

Note-se, entretanto, que esta análise difere da análise de Langacker, pois ele observa a alteração do tipo de controle a partir do evento representado na oração principal; no caso do estudo das construções do "querer", o evento da principal é mantido; o que é alterado é o tema - objeto do desejo.

A variação encontrada deve-se ao tipo de evento que está representado no OD oracional, o que sugere polissemia construcional, cf . Goldberg (1995, 
p.31): "construções são tipicamente associadas com uma família de significados relacionados, mais do que com um único sentido abstrato fixo" e ainda que (idem, p. 33) (...). "Em particular a análise polissêmica permite reconhecer um especial status do sentido central da construção".

A proposta de Langacker, por ser um estudo sobre controle, não abarca casos em que o complemento OD é simples. Entretanto, esta investigação não pode desconsiderá-los. A proposta, então, é que sejam aplicados à oração simples. Nesse caso, como o OD é fruto do desejo do sujeito conceptualizador, a efetividade é, então, máxima.

Sumarizando até aqui: há uma macroconstrução transitiva(A) que motiva as construções do desejo(B), que herdam algumas características de A; as especificações de B mostram que há os seguintes papéis argumentos: sujeito e predicado; e os seguintes papéis temáticos: sujeito experienciador volitivo e objeto desejado; o aprofundamento da análise mostra que o objeto desejado possa ser realizado de duas diferentes formas: por SN simples ou oracional. Nesse caso, por oração finita ou infinitiva; a aplicação dos parâmetros utilizados por Langacker mostra alteração da semântica das construções em função da alteração sintática. Tem-se, portanto uma rede construcional com a seguinte configuração:

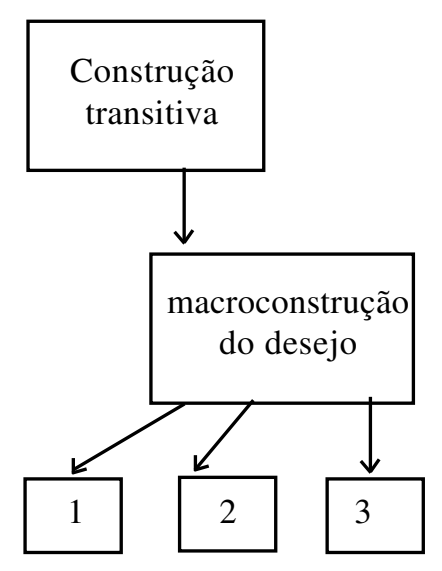

A construção transitiva motiva a macroconstrução do desejo e a domina, e são ligadas por um link de polissemia. As construções 1, 2 e 3 são motivadas pela macroconstrução e são ligadas a ela por um link de instanciação, já que são construções mais especificadas. 
CG1-

\begin{tabular}{|ccc|}
\hline sem- desejar <agt & tema $>$ \\
R: efetividade & desejador & desejo \\
Máxima & & \\
Sin- V & SUJ & OBJ(SN) \\
\hline
\end{tabular}

CG2-

\begin{tabular}{|ccc|}
\hline sem- desejar $\quad<$ agt & tema \\
R: efetividade & desejador & desejo \\
& & \\
Sin- V & SUJ & OBJ(Sinf) \\
\hline
\end{tabular}

CG3-

\begin{tabular}{|ccc|}
\hline sem- desejar & $<$ agt & tema \\
R:epistêmica & desejador & desejo \\
Sin- V & SUJ & OBJ(SF) \\
\hline
\end{tabular}

\section{A título do conclusão}

De acordo com a teoria construcional, as construções significam, tem um significado que lhes é próprio, independentemente do verbo com o qual elas se compatibilizam, ou não. Se realmente conseguimos isolar o que vimos chamando de "construções do desejo", terá de haver verbos, cuja informação semântica básica não seja a de "desejo", mas outras diferentes, que, ao se integrarem nas construções tais como descritas, como ocorre no caso do verbo "tossir", citado no início, assumirão a sentido de "querer" graças à contribuição da construção.

Assimé que testes preliminares indicam que verbos provenientes de campos semânticos tão distintos do de "querer", como estimar, presumir, supor, imaginar (verbos cognitivos) e esperar, aguardar (temporais), assumem valor de desejo quando associados às construções complexas (não com OD simples). Verifique-se:

(37) Eu [suponho, imagino, estimo,...] você vir.

(38) Eu [suponho, imagino, estimo,...] que você venha. 
Mesmo outros tipos de verbos, de diferentes naturezas sintáticas, de acordo com as descrições, como os inergativos, do tipo suspirar, assumem o valor de "querer" quando realizados na construção descrita como CG3.

(39) Eu suspiro que você chegue logo.

Emerge da análise, entretanto, que há diferenças no grau de produtividade e especificidades entre as diferentes construções. Mas isso fica para ser verificado futuramente.

\section{Notas}

${ }^{1}$ O NEMP, coordenado pelo Prof. Dr. Carlos Alexandre Gonçalves e por mim, funciona na Faculdade de Letras da UFRJ e vem desenvolvendo pesquisas e análises na interface morfologia-semântica, sob a ótica do Modelo das Construções Gramaticais. Como exemplo, verifique-se a tese de doutorado de Mauro José Rocha sobe as vogais temáticas nominais (UFRJ-2006).

${ }^{2}$ OBL significa "oblíquo", que pode ser realizado por meio ou de um sintagma prepositivo ou de um adverbial.

${ }^{3}$ Essa proposta de Langacker me foi apresentada gentilmente pela Dra. Lílian Ferrari, a quem agradeço a contribuição. Evidentemente, quaisquer equívocos de aplicação e análise são de minha inteira responsabilidade.

\section{Bibliografia básica}

ALMEIDA, Maria Lúcia Leitão de. Anguladores: a categoria e sua relação com a modalidade. Projeto de Pós-doutorado, 2004a. [mimeo]

ALMEIDA, Maria Lúcia Leitão de. Mesclas conceptuais e a compressão de informações: o caso dos anguladores. Projeto integrado encaminhado e aprovado pelo ao CNPq, 2004b. [mimeo]

ALMEIDA, Maria Lúcia Leitão de. Construções Gramaticais do Português sob a ótica da Lingüística Cognitiva. Trabalho apresentado na mesa-redonda "Construções Gramaticais: do léxico à gramática". III Conferência Internacional de Lingüística Cognitiva. UNICAMP, 2006

CHOMSKY, Noam. Lectures on government and binding. Dordrecht: Foris, 1981. 
CROFT, William. Radical Construction Grammar. New York: Oxford University Press, 2001.

CROFT, William; CRUSE, Alan. Cognitive linguistics. Oxford: Oxford University Press, 2004.

CULICOVER, P. W. Syntatic Nuts: Hard Cases in Syntax. Oxford: Oxford University Press, 1999.

DOWTY, D. Thematic Proto-Rules and Argument Selection. Language 67(3), p. 547-619, 1991.

FARRIÑA, Juan Carlos. A constructional network in appositive space. In: Cognitive Linguistics 17-1. Mouton de Gruyter, Berlin, New York, 2006.

FILLMORE, C. The Mecanism of "Constructin Grammar". BLS14, p. 35-55, 1988.

FILLMORE, C.; KAY, P. Regularity ad Idiomaticity in Grammatical, Constructions: the case of Let Alone. Language 64, p. 501-538, 1993.

FAUCONNIER, Gilles. Mappings in thought and language. Cambridge: Cambridge University Press, 1997.

FAUCONNIER, Gilles; SWEETSER, Eve. (Ed.). Spaces, worlds, and grammar. Chicago: The University of Chicago Press, 1996.

FAUCONNIER, Gilles; TURNER, Mark. The way we think: conceptual blending and the mind's hidden complexities. New York: Basic Books, 2002.

GOLDBERG, A. Constructions: A Construction Grammar Approach to Argument Structure. Chicago: Chicago University Press, 1995.

GOLDBERG, A. Constructions at work. The nature of generalization in language. Oxford University Press, 2006.

HUTCHINS, E. Cognition in the Wild. Cambridge, Mass.: MIT Press, 1995a.

GONÇALVES. Processos morfológicos não-concatenativos sob a ótica da Teoria da Otimalidade. Projeto encaminhado e aprovado pelo CNPq, 2004.

KAY, Paul. Words and the grammar of context. California: CSLI Publications, 1995.

KAY, P.; FILLMORE, C. Grammatical Constructions and Linguistic Generalizations: the What's X Doing Y? construction. Language, n. 75, p. 1-33, 1999.

LAKOFF, George; JOHNSON, Mark. Metaphors we live by. Chicago: The University of Chicago Press, 1980. 
LAKOFF, G. Women, Fire and Dangerous things. Chicago: The University of Chicago Press, 1987

LANGACKER, R. Foundations of Cognitive Grammar. v.1. California: Stanford University Press, 1987.

LANGACKER, R. Conferência no Congresso Internacional de Lingüística Cognitiva. Cracóvia, Polônia, 2007. (Não publicada)

LAKOFF; JONHSON (1999). Philosophy in the Flesh. Chicago: The University of Chicago Press, 1980.

MANDELBLIT, Nili. Gramatical Blending: Creative and Schematic Aspects in Sentence Processing and Translation. Ph.D. (Dissertation) - University of California, San Diego, 1997.

SILVA, A. Soares. A semântica do "deixar": uma contribuição para a abordagem cognitiva em Semântica Lexical. Dissertação (Doutorado) - Universidade Católica de Filosofia, Braga, 1997.

SALOMÃO, Maria Margarida Martins. O processo cognitivo da mesclagem na análise lingüística do discurso. Rio de Janeiro/Juiz de Fora. Projeto Integrado de Pesquisa, 1999.

TOMASELlO, M. The Cultural Origins of Human Cognition. Cambridge, MA: Harvard University Press, 2000. 